\title{
Seroprevalencia de anticuerpos contra el poliovirus 1 en niños mexicanos
}

\author{
Juan Ruiz-Gómez, MC,(1) José Luis Valdespino, MC, MSP,(2) Gustavo Olaiz-Fernández, MC, MSP,(3) \\ Eloísa Arias-Toledo, Ing Biot, ${ }^{(1)}$ Jaime Sepúlveda, MC, M en C, D en C.(I)
}

\section{Ruiz-Gómez J,Valdespino JL, Olaiz-Fernández G, Arias-Toledo E, Sepúlveda J. Seroprevalencia de anticuerpos contra el poliovirus I en niños mexicanos. Salud Publica Mex 2007;49 supl 3:S36I-S369.}

\begin{abstract}
Resumen
Objetivo. Analizar la frecuencia y distribución de la prevalencia de anticuerpos contra el virus de la poliomielitis tipo I en niños menores de 10 años en México, además de contribuir a la evaluación del programa de vacunación. Material y métodos. Se estudió la presencia de anticuerpos contra el poliovirus tipo I en una muestra de la Encuesta Nacional de Salud 2000. Los sueros se recolectaron entre noviembre de 1999 y junio de 2000 a nivel nacional. La muestra constó de 6270 niños de uno a nueve años de edad y se utilizó la técnica de neutralización. Resultados. La seropositividad fue de $99.3 \%$ (IC95\%99.I-99.7). Se identificaron como factores de riesgo de susceptibilidad el analfabetismo $(R M=1.5, p=$ $0.002)$ y el bajo ingreso familiar $(R M=1.4, p=0.0487)$ y como factor protector el acceso a la seguridad social $(R M=$ $0.4 I, p=0.04$ ). Conclusiones. Las actividades del programa de vacunación que han llevado a cabo las instituciones de salud han dado resultados en el control y eliminación de la enfermedad. Sin embargo, los programas de vacunación no deben interrumpirse, incluso si se ha registrado $99.3 \%$ de seropositividad; no puede soslayarse que al convertir el $0.7 \%$ restante, se calcula que hay 190000 niños susceptibles de contraer la enfermedad. Estos niños se localizan sobre todo en el sur del país.
\end{abstract}

Palabras clave: anticuerpos contra poliovirus I;seroepidemiología de la poliomielitis; VOP; México
Ruiz-Gómez J,Valdespino JL, Olaiz-Fernández G, Arias-Toledo E, Sepúlveda J.

Seroprevalence of antibodies

against poliovirus type I in Mexican children.

Salud Publica Mex 2007;49 suppl 3:S361-S369.

\begin{abstract}
Objective. To analyze the frequency and distribution of the prevalence of antibodies against the poliomyelitis type I virus in children I-9 years old in Mexico. Material and Methods. Antibodies against poliovirus type I (neutralization method) were studied in 6270 sera selected from the 24232 sera from children one to nine years old, collected by the 2000 National Health Survey (ENSA 2000) that was conducted from November 1999 to June 2000. Results. Overall seroprevalence was 99.3\% (95\% Cl: 99.I-99.7). Using bivariate analysis, absence of antibodies was shown to be associated with illiteracy $(O R=$ $1.5, p=0.002)$ and low household income $(O R=1.4, p=0.0487)$, while those children having access to social security $(O R=$ $0.41 p=0.04$ ) had a higher likelihood of having protective antibodies. Conclusions. The vaccination program activities conducted by health institutions have been successful in the control and eradication of the disease. However, a note of caution is necessary since the expansion of data reveals that although seroprevalence of antibodies has an upper limit of $99.3 \%, 0.7 \%$ of children (roughly 190000 ) are susceptible to developing the disease. Most of these children live in the southern regions of the country.
\end{abstract}

Key words: antibodies against poliovirus type I; seroepidemiology of poliomyelitis; OPV; Mexico

(I) Instituto Nacional de Salud Pública. México.

(2) Instituto Nacional de Salud Pública; actualmente en el Laboratorio de Biológicos y Reactivos de México (Birmex).

(3) Secretaría de Salud. México.

Fecha de recibido: 2 de febrero de 2006 - Fecha de aprobado: 10 de noviembre de 2006 Solicitud de sobretiros: Dr. Juan Ruiz Gómez. Instituto Nacional de Salud Pública.Av. Universidad 655, Col. Santa María Ahucatitlán. 62508, Cuernavaca, Morelos, México. Correo electrónico:jruiz@correo.insp.mx 
L os enterovirus pertenecen a la familia Picornaviridae y comprenden más de 60 serotipos, entre los cuales se incluyen los poliovirus, coxsackievirus y echovirus. ${ }^{1-4}$ La infección por poliovirus en seres humanos puede deberse a tres serotipos deferentes y casi siempre es subclínica o se relaciona con síntomas inespecíficos. La parálisis flácida aguda ocurre entre 0.1 y $1 \%$ de los casos de infección natural y puede ocasionar la muerte o una discapacidad por toda la vida. ${ }^{5}$ El último caso de poliomielitis paralítica que notificó la Organización Mundial de la Salud (OMS) para América se identificó en Perú en 1991. En 1994, una comisión internacional independiente certificó que el hemisferio occidental era una zona libre del poliovirus endémico. ${ }^{6,7}$ La OMS propuso como objetivo la erradicación mundial de la poliomielitis para el año 2005; 1,8 empero, hay lugares como la India, Pakistán, Afganistán y algunos países de África en los que la poliomielitis persiste como resultado de las bajas coberturas de vacunación con dosis óptimas.

En México, la poliomielitis paralítica se ha eliminado como resultado de la aplicación de múltiples dosis de vacuna oral atenuada. Existen evidencias de la recepción masiva de 15 dosis de vacuna trivalente en niños mexicanos a través de las acciones intensivas, como las semanas nacionales de salud y las habituales de vacunación. ${ }^{9}$ No se han informado casos de parálisis por cepas silvestres desde octubre de 1990.6,7,10 Los primeros resultados se obtuvieron por la campaña de vacunación masiva llevada a cabo en 1972, en la cual se vacunó a más de $70 \%$ de los niños menores de cinco años. ${ }^{10}$ En 1986, tal y como lo propuso la Organización Panamericana de la Salud (OPS), México adoptó la medida de los Días Nacionales de Vacunación y ello redujo los casos de 2 por cada millón en el periodo de 1983 a 1985 a 0.8 en 1986 y 0.3 en 1988. ${ }^{11}$ Se sabe, además, que los programas de vacunación propiciaron la presencia de poliovirus en la población: el tipo 1 es el serotipo más aislado en las poblaciones en las cuales existen aún bajas coberturas de vacunación y los tipos 2 y 3 se presentan en las poblaciones muy inmunizadas. En México, los últimos casos de poliomielitis paralítica comunicados en el periodo 1989-1990 se relacionaron con el poliovirus silvestre tipo $3 .^{12}$

En los países donde la poliomielitis por el poliovirus tipo silvestre se ha eliminado se ha reevaluado continuar el uso sistemático de la vacuna oral antipoliomelítica (VOP) debido a la posibilidad de ocurrencia de poliomielitis paralítica vinculada con la vacunación; esto, si bien poco frecuente, puede dar lugar a casos de parálisis por cepas vacunales. Varios de los países han cambiado sus programas regulares de vacunación contra la polio- mielitis con el uso de la vacuna de virus inactivado(VPI) que se considera más segura. ${ }^{13}$ Las ventajas del empleo de la VPI incluyen seguridad, alto nivel de inmunogenicidad a largo plazo y la posibilidad de combinarla con otras vacunas. ${ }^{14-16}$ Se sabe que tres dosis de VPI producen una inmunidad $\geq 99 \%$, cifra que es semejante a la obtenida con 10 o más dosis de VOP. ${ }^{15,16}$ Sin embargo, la VPI presenta algunas desventajas, como una pobre inmunidad intestinal y falta de inmunización indirecta a los contactos secundarios de los vacunados por la circulación de cepas atenuadas vivas, lo que ha representado problemas para su incorporación en los países en desarrollo. Aunque las disposiciones de la OMS para la erradicación global consideran tan sólo el uso de la vacuna VOP, el posible reemplazo de ésta por la VPI o esquemas mixtos ha sido motivo de discusión durante los últimos años. ${ }^{15-17}$ La eliminación de la polio en el hemisferio occidental y la notable disminución de la incidencia de la enfermedad en el resto del mundo han modificado el equilibrio existente entre los casos secundarios a la vacunación con VOP respecto del riesgo de infección natural; esto es un nuevo capítulo en la controversia VOP-VPI. ${ }^{14-16,18}$

La erradicación mundial de la poliomielitis requiere acciones en varios planos, sobre todo en cuanto al aseguramiento y mantenimiento de altos niveles de cobertura en la vacunación contra la polio, en particular en niños menores de cinco años, y a una eficiente medida del sistema de vigilancia para los casos de parálisis flácida aguda (PFA) en los niños menores de 15 años. El control de calidad de la producción de las vacunas, la notificación de los casos y la vigilancia epidemiológica que permitan la detección de la prevalencia de anticuerpos en la comunidad son de gran importancia en un esquema de control y vigilancia de la enfermedad. Más aún, con la posibilidad cercana de la erradicación mundial de la poliomielitis resulta necesaria la discusión de diversos programas. Mientras se avanza en la erradicación mundial de la poliomielitis, la administración efectiva y la evaluación de los programas de vacunación son un aspecto fundamental. ${ }^{19}$

En una encuesta sobre la prevalencia de anticuerpos contra la poliomielitis para los tres tipos de poliovirus (1, 2 y 3), en la población de uno a cinco años de edad en México, se recolectaron en 1987 los sueros provenientes de la Encuesta Nacional Seroepidemiológica y se procesaron, mediante la técnica de neutralización, 5260 muestras para análisis de anticuerpos contra poliomielitis. Los niveles de inmunidad notificados a nivel nacional para los tres tipos de poliovirus fueron los siguientes: tipo 1,89.8\%; tipo 2, 97.6\%; y tipo 3, 85.4\%. El antecedente vacunal, referido de forma verbal como la recepción 
de tres o más dosis, mostró diferencias significativas; los vacunados registraron seroprevalencias de 92.7, 98.6 y $88.8 \%$ y los no vacunados de $80.6,94.1$ y $74.1 \%$ para cada uno de los tres tipos de poliovirus. ${ }^{10}$

\section{Material y métodos}

El presente trabajo analiza los resultados de una encuesta seroepidemiológica llevada a cabo en una población de 6270 niños mexicanos de 1 a 9 años con la finalidad de evaluar los títulos de anticuerpos protectores contra el poliovirus tipo 1.

Se seleccionó el poliovirus tipo 1 en este estudio porque es el serotipo de mayor circulación en las zonas del mundo donde aún no se ha erradicado la enfermedad y se puede aislar su tipo silvestre del medio. Además, se ha mostrado que es el causante de la mayor parte de los casos presentados en fecha reciente. ${ }^{20-25}$ Por lo tanto, en un hipotético caso importado, el serotipo 1 sería el más identificado. De manera adicional, los anticuerpos contra este serotipo son los esperados con una proporción intermedia. Por otro lado, los tipos 2 y 3 se hallan en comunidades muy inmunizadas y se vinculan con la poliomielitis paralítica por vacunación. ${ }^{10}$ Estudios como éste proveen información epidemiológica útil que puede ayudar en las decisiones acerca de la lucha contra la poliomielitis y la evaluación de las políticas de vacunación en los contextos nacional e internacional.

\section{Estudio poblacional}

Se seleccionó una muestra aleatoria de 6270 sueros pertenecientes a niños de 1 a 9 años de edad del banco de sueros de la Encuesta Nacional de Salud 2000 alojado en el Instituto Nacional de Salud Pública. La etapa de recolección de esta encuesta se efectuó durante ocho meses entre 1999 y 2000. El diseño del muestreo siguió un modelo de conglomerados probabilístico, multietápico y estratificado. El tamaño de muestra se calculó tras considerar los parámetros estudiados, el nivel de confiabilidad deseado y el máximo valor de error aceptado. Se muestreó un total de 43479 hogares y se recogieron datos acerca del estado de salud, registro de inmunizaciones, condiciones de vida y situación socioeconómica. Al mismo tiempo, se tomaron muestras clínicas y se realizaron mediciones médicas. Se revisaron los cuestionarios, se corrigieron los problemas de información y se capturaron los datos. Se creó una base de datos para la administración de los sueros en el banco de datos, el cual contiene más de 80000 muestras almacenadas a $-150^{\circ} \mathrm{C}$ hasta su uso.
Métodos de laboratorio: titulación de anticuerpos contra el poliovirus tipo 1 por neutralización

Los sueros se diluyeron 1:8 en medio mínimo Eagle esencial, que contenía $0.11 \%$ de $\mathrm{NaHCO}_{3}, 4 \%$ de suero fetal de carnero y $50 \mu \mathrm{g} / \mathrm{ml}$ de gentamicina (medio de mantenimiento), y se incubaron a $56^{\circ} \mathrm{C}$ durante $30 \mathrm{mi}$ nutos para inactivar el complemento. Se distribuyeron alícuotas de $25 \mu$ de cada suero diluido en placas de 96 pozos. A cada muestra se le añadió un volumen igual de una suspensión del poliovirus tipo 1 estándar regional (Lote C-17, OMS / OPS) que contenía $100 \mathrm{DICT}_{50} / 0.025$ $\mathrm{ml}$; se incluyeron controles de toxicidad sérica en cada caso. Las mezclas se incubaron durante tres horas a $35^{\circ} \mathrm{C}$, con $5 \%$ de $\mathrm{CO}_{2}$ y se almacenaron toda la noche a $4^{\circ} \mathrm{C}$. Las células Hep 2 se diluyeron a $150000 \mathrm{cel} / \mathrm{ml}$ en medio de mantenimiento y se añadieron alícuotas de $100 \mu l$ de esta suspensión celular a cada pozo. Después de mezclar de forma cuidadosa las placas, se incubaron durante siete días a $35^{\circ} \mathrm{C}$. Al término de este tiempo, las células se fijaron y tiñeron con una mezcla de $4.5 \%$ de formaldehído, $10 \%$ de etanol y $1.2 \mathrm{mg} / \mathrm{ml}$ de cristal violeta en PBS durante 30 minutos; se lavaron y se analizaron con ayuda del microscopio invertido en búsqueda de efectos citopáticos (ECP). Los pozos que no se tiñeron se consideraron positivos para ECP. Los sueros con títulos menores o iguales a 1:8 se retitularon con diluciones en base dos, primero con la muestra sin diluir y luego hasta la dilución 1:128. Se incluyeron controles de toxicidad sérica para cada dilución y los títulos de virus se determinaron por el método de Spearman-Karber y se expresaron en DICT $_{50}{ }^{26-28}$

La dilución del suero de 1:8 se seleccionó como valor de corte para la seropositividad porque es el que recomienda la $\mathrm{OMS}^{26}$ como indicador de protección. Sin embargo, algunos autores ${ }^{29}$ proponen que cualquier título detectable de anticuerpos neutralizantes contra polio puede considerarse como protector contra la enfermedad paralítica clínica. Con esta recomendación en mente, los sueros que mostraron títulos iguales o menores a 1.8 en la búsqueda inicial se retitularon.

\section{Análisis de los datos}

Los datos se introdujeron en una base de datos electrónica y se analizaron con el paquete SPSS y Stata. Los datos se organizaron en cuadros y gráficas y el análisis de variables se consideró por grupo de edad (1-4 y 5-9 años de edad), género, existencia de cartilla de vacunación y área de residencia (rural o urbana). Las áreas urbanas se definieron como las que tienen $\geq 15000$ habitantes $y$ 
las rurales aquéllas con menos de 15000 habitantes. Las respuestas "por interrogatorio" sobre los antecedentes vacunales no se registraron en el cuestionario y sólo se consideraron las dosis documentadas como válidas y captadas en la base de datos. Sin embargo, todas las muestras de suero, al margen de su documentación previa sobre vacunación, se probaron en el laboratorio y analizaron. Los niños de los que se carecía de información (falta de cartilla de vacunación o número de dosis recibidas) se excluyeron del análisis de datos. El análisis de las variables se basó en proporciones, nivel de seropositividad y susceptibilidad por grupo de edad, género, área de residencia y dosis de vacunas recibidas. Se calcularon los intervalos de confianza de 95\% (IC95\%) y los valores de $p$. Las comparaciones se hicieron con la prueba de la ji cuadrada o la prueba exacta de Fischer cuando fue apropiado.

\section{Resultados}

Los sueros de 6270 niños de 1 a 9 años de edad se ensayaron en la búsqueda de anticuerpos contra el poliovirus tipo 1 . Se reconocieron niveles de anticuerpos mayores de 1:8 en 6228 individuos y ello permitió calcular una seropositividad total de $99.3 \%$ (IC95\% 99.2-99.8). No hubo diferencias significativas en la seropositividad por género: 99.4\% (IC95\% 99.0-99.6) para niños y 99.3\% (IC95\% 98.8-99.6) para niñas; tampoco por grupo de edad: $99.6 \%$ (IC95\% 99.2-99.8) y 99.2\% (IC95\% 98.8-99.5) para los niños de 1 a 4 y 5 a 9 años, respectivamente (figura 1, cuadro I).

De todos los niños que se incluyeron en el estudio, se sabía que 4665 (74.4\%) tenían el antecedente de vacu-

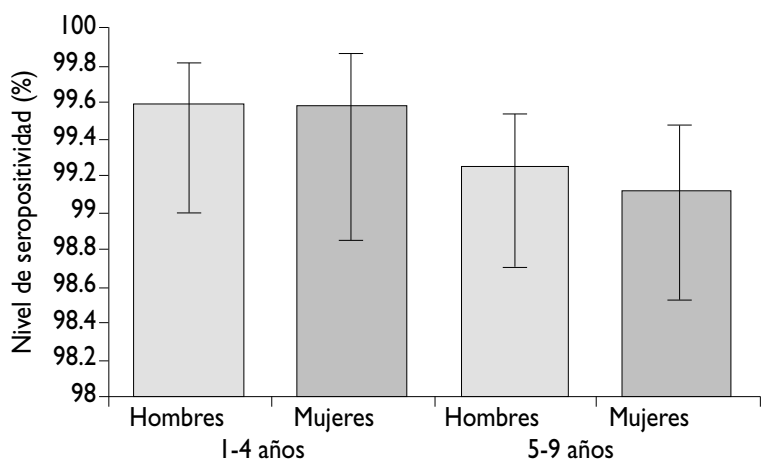

Figura I. Porcentaje de seropositividad al poliovirus TIPO I POR GRUPO DE GÉNERO Y EDAD. NO HAY DIFERENCIAS ESTADÍSTICAS SIGNIFICATIVAS EN RELACIÓN CON ESTOS DOS factores. Las barras MUeStran IC95\%(MÉxico, 19992000)

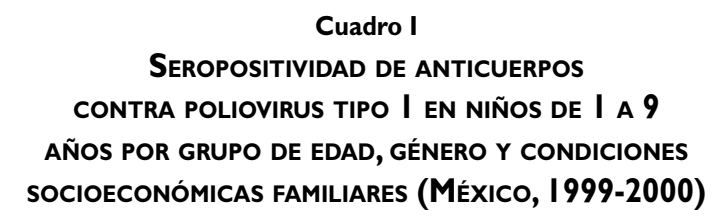

Características
de la población
estudiada

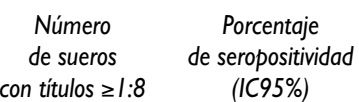

$p$

Grupo de edad (años)

\begin{tabular}{llll}
$1-4$ & $2390 / 2400$ & $99.58(99.19,99.79)$ & 0.0563 \\
\hline $5-9$ & $3838 / 3870$ & $99.17(98.77,99.45)$ &
\end{tabular}

Género

\begin{tabular}{llll} 
Masculino & $3161 / 3181$ & $99.37(98.98,99.61)$ & 0.7116 \\
\hline Femenino & $3067 / 3089$ & $99.29(98.82,99.57)$ &
\end{tabular}

Área de residencia

\begin{tabular}{llll} 
Urbana & $3260 / 3271$ & $99.66(99.30,99.84)$ & 0.0062 \\
\hline Rural & $2968 / 2999$ & $98.97(98.46,99.31)$ &
\end{tabular}

Alfabetismo de la cabeza de familia

\begin{tabular}{lrrr} 
Sí & $5740 / 5771$ & $99.46(99.20,99.64)$ & 0.0002 \\
\hline No & $480 / 491$ & $97.76(95.90,98.79)$ &
\end{tabular}

Seguridad social

\begin{tabular}{llll} 
Sí & $2504 / 2513$ & $99.64(99.17,99.85)$ & 0.0399 \\
\hline No & $3724 / 3757$ & $99.12(98.72,99.40)$ &
\end{tabular}

Ingresos de la familia por mes (pesos)

\begin{tabular}{llll} 
I. 0 - I I00 & I 3 I7/I 329 & $99.10(98.50,99.46)$ & 0.0488 \\
\hline II. I I0I-2 383 & I $659 /$ I 673 & $99.16(98.50,99.46)$ & \\
\hline III. $2384-4549$ & I $675 /$ I 689 & $99.17(98.52,99.54)$ & \\
\hline IV. $\geq 4500$ & I $546 /$ I 548 & $99.87(99.47,99.97)$ &
\end{tabular}

nación con tres o más dosis de VOP. Es importante hacer notar que de 1561 niños (de los cuales 23 presentaban títulos $\leq 1: 8)$ no se tenía información disponible sobre sus antecedentes de vacunación. Se observaron diferencias en la seropositividad de niños con tres dosis de VOP (98.4\%, IC95\% 95.7-99.4) y niños con más de tres (99.7, IC95\% 99.4-99.8). Aún más, 40 niños con esquemas de vacunación incompletos que habían recibido sólo una o dos dosis de VOP mostraron seropositividad mayor de 1:8. El mismo nivel se encontró en cuatro casos de niños que no habían recibido ninguna dosis de la vacuna (cuadro II). Estos niños tenían uno, cuatro, seis y siete años.

Los sueros que mostraron títulos iguales o menores de 1:8 se retitularon en la búsqueda inicial y se recalcularon los niveles de seropositividad, incluidos ahora los sueros que no tenían anticuerpos detectables 


\section{Cuadro II \\ Niveles de SERopositividad en NiÑos \\ DE I A 9 AÑOS DE EDAD PARA POLIOVIRUS \\ TIPO I DE ACUERDO CON LAS DOSIS DOCUMENTADAS DE VOP (MÉXICO, 1999-2000)}

\begin{tabular}{lll}
$\begin{array}{c}\text { Dosis documentadas } \\
\text { de VOP }\end{array}$ & $\begin{array}{c}\text { Suero con títulos } \\
\geq 1: 8\end{array}$ & $\begin{array}{c}\text { Nivel de seropositividad } \\
\text { (95\% IC) }\end{array}$ \\
0 & $4 / 4$ & 100 \\
\hline I-2 & $40 / 40$ & 100 \\
\hline 3 & $245 / 249$ & $98.39(95.66,99.42)$ \\
\hline$>3$ & $4395 / 4410$ & $99.66(99.41,99.81)$ \\
& $4684 / 4703$ & $99.60(99.35,99.75)$ \\
Total* &
\end{tabular}

(99.84\%); los anticuerpos contra el poliovirus tipo 1 no se identificaron en 10 niños, cinco de los cuales tenían un año de edad.

En este estudio se encontró a 42 niños susceptibles, es decir, un nivel de susceptibilidad menor de $1 \%(0.67 \%)$ en la población estudiada. Al extrapolar los datos es posible calcular que el número de niños susceptibles en la población nacional es de 190000 individuos, de los cuales 114500 estarían en edad escolar. Los niños que viven en comunidades rurales mostraron un riesgo de susceptibilidad tres veces mayor que los niños que viven en las áreas urbanas $(\mathrm{RM}=3.094, p=0.0062)$. Aún más, el bajo ingreso familiar $(\mathrm{RM}=1.443, p=0.0487)$ o la falta de seguridad social $(\mathrm{RM}=2.463, p=0.04)$ se identificaron como factores de riesgo de susceptibilidad. Los niños que tienen sólo tres dosis de la VOP muestran un mayor riesgo de ser susceptibles en comparación con aquellos niños con tres o más dosis; pese a ello, la diferencia no fue estadísticamente significativa en términos de los valores de las pruebas estadísticas (cuadro III): en un análisis geográfico se identificó que los individuos susceptibles se hallaban en cuatro entidades federales (Chiapas, Guerrero, Jalisco y Michoacán) y la más alta frecuencia de susceptibilidad en la región sureste del país.

\section{Conclusiones}

El nivel elevado de seropositividad contra poliovirus tipo 1 en niños mexicanos es un indicador del éxito de los programas de vacunación en el país. El tipo 1 se usó como un indicador epidemiológico de la inmunidad poblacional contra el poliovirus, ya que en el hipotético caso de la importación de cepas silvestres este serotipo sería el que se identificaría con mayor probabilidad porque ha sido el causante de la mayor parte de los brotes recientes en el mundo. Los casos sin anticuerpos detectables se redujeron a sólo 10, lo que resulta en una seropositividad de la población estudiada de $99.84 \%$. La mitad de los casos con ausencia de anticuerpos corresponde a niños menores de un año, lo cual podría reflejar la posible interferencia debido a la presencia de anticuerpos maternos al tiempo de la vacunación. ${ }^{30} \mathrm{La}$ presunción de que se requiere una cobertura de inmunización de $90 \%$ para lograr la protección de rebaño en poliomielitis es ahora controversial, en virtud de la aparición de casos de poliomielitis paralítica relacionada con virus de las cepas silvestre y vacunal a pesar de estas coberturas. ${ }^{15,16}$

Debido al pequeño número que representan los individuos no vacunados, no es posible observar una relación entre la vacunación y los niveles de seropositividad, dadas las altas coberturas de vacunación, lo que impide una comparación estadísticamente válida. Además, la falta de información sobre los antecedentes de vacunación puede atribuirse a un sesgo de memoria de los padres o tutores, los cuales no tenían disponible la cartilla de vacunación durante la entrevista.

El hecho de que no se observen sueros negativos en los niños con dos o menos dosis de la VOP podría deberse a un efecto atribuible a que la transmisión de cepas vacunales, las cuales se aplican en las fases intensivas de vacunación y que por norma no se consignan en la cartilla de vacunación.

El número de sueros negativos que corresponde a niños que recibieron múltiples dosis, de las cuales tres o más se registran en la cartilla, puede ser evidencia de la baja proporción de fracaso de la vacunación. Esta última puede ocurrir por problemas de administración, como la cadena de frío o una falta de respuesta del individuo a la vacuna. Se ha informado la falta de protección en sujetos inmunizados ${ }^{31}$ y también la disminución de títulos de anticuerpo contra poliovirus en adultos jóvenes. ${ }^{19,32}$ Se descarta la posibilidad de problemas de inmunodeficiencia en estos niños debido a que tuvieron respuestas positivas a otros inmunógenos estudiados en ellos mismos.

Aun cuando la diferencia no es estadísticamente significativa, el hecho de que los niños con tres dosis de VOP registradas muestren un alto riesgo de susceptibilidad al compararlos con niños con más de tres dosis es una coincidencia con las observaciones ${ }^{33,34}$ según las cuales los niños de naciones en desarrollo y países tropicales requieren más de tres dosis de la vacuna para obtener al menos $80 \%$ de seroconversión. Este aspecto refuerza la importancia de las actividades de inmunización suplementarias en México y tal vez en otros países en desarrollo, con la finalidad de mantener bajos niveles de susceptibilidad en la nación. 


\section{Cuadro III}

Factores de riesgo de la susceptibilidad* al poliovirus tipo I en niños mexicanos (México, 1999-2000)

\begin{tabular}{|c|c|c|c|c|}
\hline Factor de riesgo & $n$ & Porcentaje de susceptibilidad* & Razón de momios RM (IC95\%) & $p$ \\
\hline \multicolumn{5}{|c|}{ Grupo de edad (años) } \\
\hline $5-9$ & 32 & 0.83 & $1.994(0.968,4.105)$ & 0.056 \\
\hline $\mathrm{I}-4$ & 10 & 0.42 & & \\
\hline \multicolumn{5}{|l|}{ Género } \\
\hline Femenino & 22 & 0.71 & I.I34 $(0.580,2.216)$ & 0.711 \\
\hline Masculino & 20 & 0.62 & & \\
\hline \multicolumn{5}{|l|}{ Dosis de vacuna } \\
\hline 3 & 4 & 1.6 & I.194 (I.067, I.337) & 0.9972 \\
\hline$>3$ & 15 & 0.3 & & \\
\hline
\end{tabular}

Área de residencia

\begin{tabular}{lllll} 
Rural & 31 & 1.03 & $3.094(1.326,7.220)$ & 0.0062 \\
\hline Urbana & II & 0.33 &
\end{tabular}

Alfabetismo de la cabeza de familia

\begin{tabular}{ccccc} 
No & II & 2.24 & $1.469(1.260,1.712)$ & 0.0002 \\
\hline Sí & 31 & 0.54 &
\end{tabular}

Seguridad social

\begin{tabular}{cccccc} 
No & 33 & 0.88 & $0.406(0.167,0.987)$ & 0.04 & \\
\hline Sí & 9 & 0.36 & &
\end{tabular}

Ingreso de la familia por mes (pesos)

\begin{tabular}{lllll} 
I. $0-I 100$ & 12 & 0.90 & $1.443(I .82 I, I .14)$ & 0.0487 \\
\hline II. I I0I-2 383 & 14 & 0.84 & \\
\hline III. $2384-4549$ & 14 & 0.83 & 0.13
\end{tabular}

* Se consideran susceptibles los niños con títulos inferiores a I:8.

Las niñas muestran un mayor riesgo de susceptibilidad que los niños. Las diferencias por edad en los segundos indican que en los límites de edad de 5 a 9 años son más propensos a tener títulos de anticuerpos antipolio más bajos que los niños de 1 a 4 años de edad. Los análisis estadísticos de grupo no permiten concluir que estas características representan un factor de riesgo para la susceptibilidad a la poliomielitis en México. Sin embargo, la pequeña diferencia en la susceptibilidad por género pueda explicarse por discriminación cultural sobre las mujeres o por la mayor declinación en los anticuerpos antipolio en las niñas.

Otro hallazgo interesante es que los niños de áreas rurales tienen niveles mayores de susceptibilidad que los niños que viven en áreas urbanas. Esto sugiere la probable menor cobertura de vacunación en las áreas rurales o la ocurrencia de mayores fallas en los sistemas de mantenimiento de las cadenas de frío.

Los indicadores socioeconómicos son un factor de riesgo significativo de la poliomielitis en México. Los niños que forman parte de familias con bajo ingreso, así como los niños que carecen de seguridad social, muestran un mayor riesgo de susceptibilidad al poliovirus. También en familias en las cuales la cabeza de familia es analfabeto se observan mayores niveles de susceptibilidad.

Al comparar los resultados de la encuesta de 2000 con los obtenidos en una encuesta similar llevada a 
cabo en 1987, se reconoce un notorio incremento de las coberturas de vacunación que pasaron de 76.7 a 99.9\% (figura 2). La mayor frecuencia de seropositividad en la encuesta de 1987 puede ser evidencia de la adquisición de anticuerpos por la circulación de cepas vacunales y silvestres. En contraste, en este informe se muestra el éxito de los programas de vacunación; en éstos el exceso de la seropositividad (en comparación con la vacunación) es mucho menor y se debe sobre todo a cepas de origen vacunal. Estos datos muestran los esfuerzos fructíferos de las autoridades de salud en el control de la poliomielitis en el país. No obstante, aún con estos niveles de seropositividad, se calcula que 190 000 niños en el país son susceptibles. Este hallazgo es importante, especialmente porque cerca de la mitad de esta población susceptible se concentra en una zona geográfica del país: la costa mexicana del Pacífico. La mayor concentración de susceptibles en comunidades remotas rurales en esta área puede significar una importante alerta para reforzar las campañas de vacunación en estos grupos poblacionales.

Una medida necesaria para México es la introducción de la VPI y la cancelación de la vacunación VOP. Los aspectos sobre el costo-beneficio y la seguridad poblacional deben dictar las políticas existentes de vacunación. ${ }^{14}$ En este sentido, se han definido algunos criterios que deben cumplirse antes de que se introduzcan cambios en los esquemas de vacunación. ${ }^{35}$

Un componente fundamental de la supervisión efectiva del poliovirus silvestre es aún la vigilancia sobre la parálisis flácida aguda (PFA), ${ }^{36}$ que en México se realiza de forma sistemática; los últimos datos muestran que en

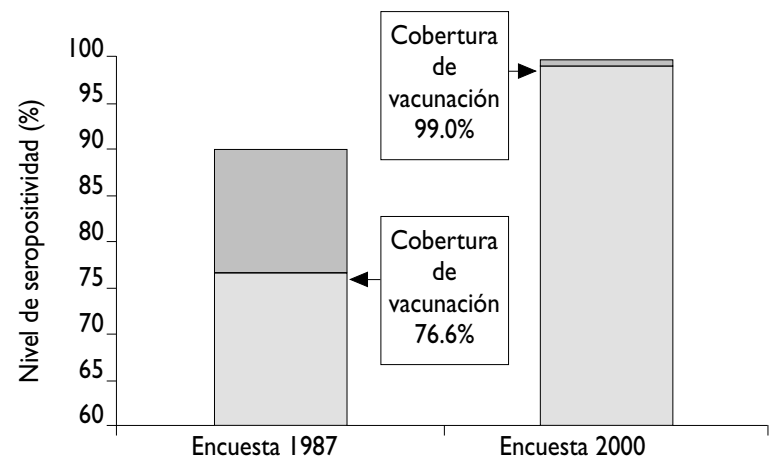

Figura 2. Porcentaje de seropositividad al poliovirus TIPO I Y COBERTURAS DE VACUNACIÓN EN LAS DOS ENCUESTAS LLEVAdAs A CABO CON NIÑOS MEXICANOS DE I A 9 aÑos (1987 Y 2000). LAS ÁREAS EN GRIS OSCURO MUESTRAN EL EXCESO DE LOS NIVELES DE SEROPOSITIVIDAD EN RELACIÓN CON la cobertura de la vacunación (MéXico, 1999-2000)
2003 hubo 368 casos, 261 casos en 2004, 257 en 2005 y 298 hasta septiembre de 2006; la OPS notificó siete aislamientos de poliovirus vacunal. ${ }^{37,38} \mathrm{El}$ riesgo de presentación de un caso de poliomielitis paralítica relacionada con VOP es de 1 caso por 2.39 millones de primera dosis y de 1 caso por cada 13.03 millones de dosis.

La vigilancia ambiental puede ofrecer datos suplementarios sustanciales, sobre todo cuando las redes de vigilancia se establecen en comunidades grandes y no es adecuada la supervisión de la parálisis flácida aguda. ${ }^{39}$ Sin embargo, la presencia de grandes cantidades de virus derivados de la VOP en muestras ambientales reduce la sensibilidad de este tipo de vigilancia y se requieren pruebas rápidas para diferenciar entre los tipos silvestres y las cepas vacunales. ${ }^{40,41}$

De acuerdo con la OMS, debe lograrse una cobertura de vacunación elevada y estable ( $90 \%$ o más) por distrito o país . En México, las coberturas de inmunización con VOP han alcanzado niveles de $95 \%$ en los últimos años. ${ }^{42}$

Es esencial la capacidad del país para invertir en los programas de vacunación. En este sentido, el uso de vacunas combinadas (DPT-Hib, HBV, IPV) puede reducir los problemas logísticos y de costo.

Este estudio tiene las limitaciones propias de un diseño transversal. El indicador obtenido es la prevalencia acumulada de anticuerpos contra el poliovirus 1 y por tanto no es una tasa. Los altos niveles de títulos protectores podrían reflejar los títulos en la población de niños mayores que han sobrevivido, en comparación con la presuposición de que los niños con títulos menores no lo hicieron.

Estudios como éste suministran información básica que no sólo refuerza las políticas nacionales, sino que favorecen las decisiones en materia de salud pública en un contexto internacional. ${ }^{24,43-46}$ En este caso, aun cuando se ha obtenido éxito para eliminar la poliomielitis en México, se debe conceder atención a las poblaciones rurales remotas y comunidades en las que prevalecen condiciones socioeconómicas bajas. La posible concentración de poblaciones susceptibles en este tipo de grupos, en especial en la zona sureste del país, es relevante ya que esta área puede representar una de las maneras en las que la enfermedad ingresa al país.

\section{Agradecimientos}

Los autores quieren agradecer la participación de los trabajadores de campo, técnicos, personal de salud y autoridades estatales de salud que colaboraron en la ENSA-2000 en el reclutamiento y toma de muestras y datos de los participantes. Merecen también un agradecimiento los doctores Roberto Tapia Conyer, Gonzalo 
Gutiérrez, Óscar Velázquez, Elsa Sarti y Luis Juárez por su ayuda en la preparación de las alícuotas y los doctores Mario Henry Rodríguez y Carlos Conde por sus acciones gerenciales para mantener el Banco de Sueros en el INSP. Se contó con financiamiento parcial de la Secretaría de Salud y del CONACyT (Protocolo No. 37212M).

\section{Referencias}

I. Di Lonardo A, Buttinelli G,Amato C, Novello F, Ridolfi B, Fiore L. Rapid methods for identification of poliovirus isolates and determination of polio neutralizing antibody titers in human sera. JVirol Methods 2002;101(I-2):189-196.

2. Georgopoulou A, Markoulatos P, Spyrou N,Vamvakopoulos NC. Improved genotyping vaccine and wild-type poliovirus strains by restriction fragment length polymorphism analysis: clinical diagnostic implications.J Clin Microbiol 2000;38(I2):4337-4342.

3. Morens D, Pallansch MA. Epidemiology. In: Rotbart HA, ed. Human enterovirus infections. Washington:ASM Press, 1995:3-23.

4. Melnick JL. Enteroviruses: poliovirus, coxsackieviruses, echoviruses and newer enteroviruses. Virology 1996:655-712.

5. Reimerink JH, van der Avoort HG, van Loon AM, Koopmans MP. Genetic basis for immunological aberrations in poliovirus Sabin serotype 3 strains imported in the netherlands.J Clin Microbiol 1999;37(8):2393-2398. 6. Wood DJ, Sutter RW, Dowdle WR. Stopping poliovirus vaccination after eradication: issues and challenges. Bull World Health Organ 2000;78(3):347-357.

7. Hull HF,Ward NA, Hull BP, Milstien JB, de Quadros C. Paralytic poliomyelitis: seasoned strategies, disappearing disease. Lancet 1994;343(8909): | 33|-|337.

8. Maurice J. Polio eradication-the last and toughest I\%. Bull World Health Organ 2001;79(6):582.

9. Mascareñas A, Salinas J, Tasset-Tisseau A, Ortiz E. Polio intensive immunization week in Mexico: an economic burden assessment. Abstract no. 384. World Congress of Pediatric Infectious Diseases-WSPID. Santiago de Chile, Chile, Nov 2002.

10. Ruiz-Gómez J. Inmunoprofilaxia de la poliomielitis.Vacunas, ciencia y salud. En: Escobar-Gutiérrez A,Valdespino-Gómez JL, Sepúlveda-Amor J, eds. México: Secretaría de Salud, 1992:131-142.

II. Cardenas-Ayala VM,Vilchis-Licon H, Stetler HC, et al. Risk factors for the presistence of wild poliovirus transmission in Sinaloa, Mexico, 19841986. Bull Pan Am Health Organ 1988;22(3):227-239.

12. Ruiz-Gómez J, Tapia-Conyer R, Salvatierra B, et al. Seroepidemiología de la poliomielitis en México. Salud Publica Mex 1992;34:168-176.

13. Hovi T. Inactivated poliovirus vaccine and the final stages of poliovirus eradication. Vaccine 200I;19(I7-19):2268-2272.

14. Swennen B, Levy J. Oral poliomyelitis vaccine: time to change? Vaccine 200I;19(I7-19):2262-2267.

15. Bompart F.Vaccination strategies for the last stages of global polio eradication. Indian Pediatr 2005;42(2):163-169.

16. John TJ.A developing country perspective on vaccine-associated paralytic poliomyelitis. Bull World Health Organ 2004;82(I):53-57; discussion 57-58.

17. Sutter RW, Cochi SL, Melnick JL. Live attenuated poliovirus vaccine. In: Plotkin SA, Orenstein WA, eds.Vaccines. $3^{\text {rd }}$ ed. Philadelphia:WB Saunders, 1999:364-408.
18. Sutter RW, Suleiman AJ, Malankar P, et al. Trial of a supplemental dose of four poliovirus vaccines. N Engl J Med 2000;343(I I):767-773.

19. Grotto I, Handsher R, Gdalevich M, et al. Decline in immunity to polio among young adults. Vaccine 200I;19(30):4162-4166.

20. Kew O, Morris-Glasgow V, Landaverde M, et al. Outbreak of poliomyelitis in Hispaniola associated with circulating type I vaccinederived poliovirus. Science 2002;296(5566):356-359.

21. Shulman LM, Handsher R, Yang CF, et al. Resolution of the pathways of poliovirus type I transmission during an outbreak.J Clin Microbiol 2000;38(3):945-952.

22. Kojouharova M, Zuber PL, Gyurova S, et al. Importation and circulation of poliovirus in Bulgaria in 200I. Bull World Health Organ 2003;8I (7):476-48I.

23. Patriarca PA, Sutter RW, Oostvogel PM. Outbreaks of paralytic poliomyelitis, 1976-1995. J Infect Dis 1997;175(Suppl I):SI65-SI72. 24. Khare S, Bhatia R, Kumari S, Datta KK.Virologic surveillance of poliomyelitis in Delhi. Indian Pediatr 1996;33(9):746-750.

25. Sokhey J, Sharma B, Singh H, Sood D. Isolation of poliovirus from cases of acute flaccid paralysis. Indian Pediatr 1996;33(II):917-920.

26.WHO. Manual for the virological investigation of polio. Geneva:WHO/ EPI/GEN, 1997;97(0I)

27. Edevag G, Wahren B, Osterhaus AD, Sundqvist VA, Granstrom M. Enzyme-linked immunosorbent assay-based inhibition test for neutralizing antibodies to polioviruses as an alternative to the neutralization test in tissue culture. J Clin Microbiol 1995;33(II):2927-2930.

28. Simhon A, Lifshitz A,Abed Y, Lasch EE, Schoub B, Morag A. How to predict the immune status of poliovirus vaccinees? A comparison of virus neutralization at a very low serum dilution versus ELISA in a cohort of infants. Int J Epidemiol 1990; I9(I): 164-168.

29. Sutter RW, Pallansch MA, Sawyer LA, Cochi SL, Hadler SC. Defining surrogate serologic tests with respect to predicting protective vaccine efficacy: poliovirus vaccination. Ann NY Acad Sci 1995;754:289-299. 30. Ruiz-Gómez J, Caloca-García M, Longega-Escobio P.Anticuerpos humorales, coproanticuerpos y excreción viral en recién nacidos inmunizados con la vacuna antipoliomielítica. Salud Publica Mex 1979;21:127-134.

3I. Slater PE, Orenstein WA, Morag A, et al. Poliomyelitis outbreak in Israel in 1988: a report with two commentaries. Lancet 1990;335(8699): I 192II95; discussion II96-II98.

32. Böttiger M. Polio immunity to killed vaccine: an 18-year follow-up. Vaccine 1990;8:443-445.

33. Patriarca PA. Poliomyelitis in selected african and asian countries. Public Health Rev 1993;2I(I-2):9I-98.

34. Patriarca PA, Foege WH, Swartz TA. Progress in polio eradication. Lancet 1993;342(8885): I 46I-I 464.

35. Plotkin S,Vidor E. Poliovirus vaccine-Inactivated. In: Plotkin S, Orenstein W, eds. Vaccines. United States of America: Elsevier Inc., 2004: 625-650.

36. Manor Y, Handsher R, Halmut T, et al. Detection of poliovirus circulation by environmental surveillance in the absence of clinical cases in Israel and the Palestinian authority. J Clin Microbiol 1999;37(6): 1670-1675.

37. Unidad de Inmunización. Vigilancia de la poliomielitis en las Américas. Bol Sem Pol 2006;2I(37).

38. Dirección General de Epidemiología. Sistema de vigilancia epidemiológica de poliomielitis y parálisis flácida aguda. Mexico: Secretaría de Salud, 2006. Disponible en http://www.dgepi.salud.gob.mx/boletin/2006/ sem40/pdf/ind_pfal.pdf.

39. WHO. Fourth informal consultation on the polio laboratory network. Geneva: Department of Vaccines and other Biologicals. Geneva:WHO, 1999. 40. Guillot S, Otelea D, Delpeyroux F, Crainic R. Point mutations involved in the attenuation/neurovirulence alternation in type I and 2 oral polio 
vaccine strains detected by site-specific polymerase chain reaction. Vaccine 1994; 12(6):503-507.

4I. De L, Nottay B, Yang CF, Holloway BP, Pallansch M, Kew O.

Identification of vaccine-related polioviruses by hybridization with specific RNA probes. J Clin Microbiol 1995;33(3):562-57I.

42. Advisory Committee on Polio Eradication-standing recommendations for responding to circulating polioviruses in polio-free areas. Wkly Epidemiol Rec 2005;80(38):330-33I.

43. Hogg K, Hogg G, Lester R, Uren E. Immunity to poliomyelitis in Victorians. Aust N Z J Public Health 2002;26(5):432-436.
44. Seibil VB, Malyshkina LP, Lavrova IK, Efimova VF, Sadovnikova VN. State of collective immunity to poliomyelitis in Moscow donors. Zh Mikrobiol Epidemiol Immunobiol 2002(6):43-47.

45. Chen RT, Hausinger S, Dajani AS, et al. Seroprevalence of antibody against poliovirus in inner-city preschool children. Implications for vaccination policy in the United States. JAMA 1996;275(2I): I639-I645. 46. Diedrich S, Schreier E. Status of immunity against poliomyelitis. Polio serosurvey in 1993. Dtsch MedWochenschr 1995; I20(8):239-244. 